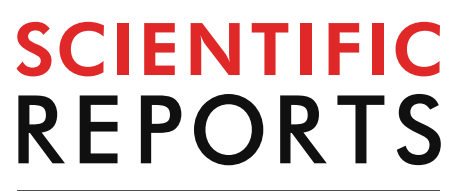

natureresearch

Check for updates

\title{
TNF genetic polymorphism (rs1799964) may modify the effect of the dietary inflammatory index on gastric cancer in a case-control study
}

\author{
Jeeeun $\mathrm{Kim}^{1,2}$, Jeonghee $\mathrm{Lee}^{1}$, II Ju Choi ${ }^{3}$, Young-II Kim ${ }^{3}$, Joohon Sung ${ }^{2}$ \& Jeongseon Kim ${ }^{1 凶}$
}

The inflammatory process is known to increase the risk of gastric carcinogenesis, and both genetic and dietary factors are associated with inflammation. In the present study of 1,125 participants ( 373 cases and 752 controls), we determined whether the dietary inflammatory index (DII) is associated with the risk of gastric cancer (GC) and investigated whether a TNF polymorphism (rs1799964) modifies this association. Semi-quantitative food frequency questionnaire derived data were used to calculate the DII scores. Odds ratios (OR) and $95 \%$ confidence intervals $(\mathrm{CI})$ were calculated using multivariable logistic models adjusted for confounders. When we stratified the data by sex, the association between GC and the DII was significant only among the women (OR, 2.27; 95\% CI 1.25-4.19), and the DII effect on the risk of GC differed depending on the TNF genotype (OR, 2.30; 95\% CI 1.27-4.24 in TT genotype; $\mathrm{OR}, 0.78 ; 95 \% \mathrm{Cl} 0.37-1.65$ in CC + CT, p for interaction $=0.035$ ). Furthermore, the association between the DII and GC was significant in the Helicobacter pylori-positive group; similarly, the effect differed based on the TNF genotype (OR, 1.76; $95 \% \mathrm{Cl} 1.13-2.73$ in TT genotype; OR,0.98; 95\% Cl 0.54-1.77 in $C T+C C$, p for interaction $=0.034$ ). In conclusion, rs1799964 may modify the effect of the DII on GC.

According to the GLOBOCAN results reported in 2018, gastric cancer (GC) is the fifth most common cancer worldwide, and the highest mortality rates are found in East Asia, including Korea ${ }^{1}$. In 2016, the incidence of GC was first and second among all types of cancer in Korea ${ }^{2}$. Such a high prevalence of GC may be attributed to Helicobacter pylori infection and chronic inflammation caused by chronic gastritis ${ }^{3}$.

The inflammatory process is caused by cytokine secretion and increases the risk of the development of gastric carcinogenesis ${ }^{4,5}$. Among these cytokines, tumor necrosis factor (TNF) is among the most important factors inhibiting gastric acid secretion, causing the development of $\mathrm{GC}^{6}$. TNF production is generally regulated at the transcriptional level ${ }^{6}$. Polymorphisms located in the promoter region of the TNF gene affect the level of TNF. Indeed, genetic polymorphisms of the TNF gene have been proposed as candidate risk factors for $\mathrm{GC}^{7}$. However, the results of studies investigating the association between TNF genetic polymorphism and GC risk have been inconsistent ${ }^{8,9}$. These results indicate the need for further studies considering other factors, such as individual lifestyle factors.

Environmental factors and host genetic factors also contribute to the chronic inflammatory response. Among these factors, dietary components contain both carcinogens and anticancer substances and are known to control the risk of cancer ${ }^{10}$. For example, the consumption of fruits, vegetables, and beans containing antioxidants has been reported to help reduce inflammation, whereas the consumption of saturated fats, refined carbohydrates, and processed meat can cause inflammation ${ }^{11,12}$. However, the analysis of a single food group or single nutrient does not cover the entire intake of an individual, and there is a limit to identifying the association with the disease ${ }^{13}$. Since the results of most studies focusing on single nutrients are inconsistent, it is necessary to assess

${ }^{1}$ Department of Cancer Biomedical Science, Graduate School of Cancer Science and Policy, National Cancer Center, Goyang-si, Gyeonggi-do 10408, South Korea. ${ }^{2}$ Division of Genome and Health Big Data, Department of Public Health Sciences Graduate School of Public Health, Seoul National University, Seoul, South Korea. ${ }^{3}$ Center for Gastric Cancer, National Cancer Center, Goyang-si, South Korea. ${ }^{\circledR}$ email: jskim@ncc.re.kr 


\begin{tabular}{|c|c|c|c|}
\hline Category & Control $(\mathrm{N}=752)$ & Case $(\mathrm{N}=373)$ & $\mathbf{P}^{*}$ \\
\hline Age & $53.8 \pm 9.12$ & $53.9 \pm 9.39$ & 0.92 \\
\hline \multicolumn{4}{|l|}{ Sex (\%) } \\
\hline Men & $487(64.8)$ & $242(64.8)$ & \multirow{2}{*}{0.96} \\
\hline Women & $265(35.2)$ & $131(35.2)$ & \\
\hline \multicolumn{4}{|l|}{ Smoking status (\%) } \\
\hline Non & $339(45)$ & $148(39.7)$ & \multirow{3}{*}{$<0.001$} \\
\hline Ex-smoker & $254(33.8)$ & $107(28.7)$ & \\
\hline Current & $159(21.2)$ & $117(31.4)$ & \\
\hline \multicolumn{4}{|l|}{ Drinking status (\%) } \\
\hline Non-current & $274(36.4)$ & $148(39.7)$ & \multirow{2}{*}{0.2} \\
\hline Current & $478(63.6)$ & $225(60.3)$ & \\
\hline \multicolumn{4}{|l|}{ Education (\%) } \\
\hline Element & $47(6.3)$ & $57(15.3)$ & \multirow{3}{*}{$<0.001$} \\
\hline Mid-high & $353(46.8)$ & $233(62.5)$ & \\
\hline University & $352(46.8)$ & $83(22.3)$ & \\
\hline \multicolumn{4}{|l|}{ Regular exercise (\%) } \\
\hline No & $337(44.8)$ & $240(64.3)$ & \multirow{2}{*}{$<0.001$} \\
\hline Yes & $415(55.2)$ & $133(35.7)$ & \\
\hline \multicolumn{4}{|c|}{ H. pylori infection (\%) } \\
\hline Negative & $448(59.6)$ & $58(15.5)$ & \multirow{2}{*}{$<0.001$} \\
\hline Positive & $304(40.4)$ & $315(84.5)$ & \\
\hline \multicolumn{4}{|c|}{ First-degree family history of cancer (\%) } \\
\hline Yes & $367(49.2)$ & $176(47.5)$ & \multirow{2}{*}{0.8} \\
\hline No & $383(50.8)$ & $197(52.5)$ & \\
\hline Total energy intake & $1717.0 \pm 549.1$ & $1929.0 \pm 662.0$ & $<0.001$ \\
\hline DII score & $0.64 \pm 2.63$ & $1.22 \pm 2.59$ & $<0.001$ \\
\hline
\end{tabular}

Table 1. General characteristics of the study participants stratified by cancer status. The values in the table indicate the mean $\pm \mathrm{SD}$ or $\mathrm{N}(\%) .{ }^{*} \mathrm{P}$-values denote the difference between the cases and controls at the $95 \%$ confidence level.

the overall effect of diet-induced inflammation reflecting the combination of nutrients consumed by individuals on the risk of cancer ${ }^{14,15}$. Moreover, the genetic sensitivity of the host can control the effects of the disease through complex interactions with environmental factors, and diets containing anticancer nutrients and carcinogens can modulate the risk of cancer development, especially in genetically vulnerable individuals ${ }^{16,17}$. Thus, gene-diet interactions can account for various outcome differences in individual GC risk, complementing the findings of studies investigating a single gene or a single diet.

In this study, we found that dietary inflammation is associated with the risk of GC. We also analyzed whether a TNF genetic polymorphism is related to the risk of GC. In particular, we focus on identifying the association between GC and a genetic polymorphism of TNF (rs1799964); the association between rs1799964 and both GC and $H$. pylori infection has been previously reported ${ }^{18,19}$. We aimed to study whether differences in individual TNF genes have different effects on GC depending on eating habits and vice versa.

\section{Results}

Study population characteristics. Table 1 presents the general characteristics of the study participants. The subjects with GC were more likely to be smokers and less likely to engage in regular exercise than the controls $(\mathrm{p}<0.001$ for all variables). In addition, the cases had lower education levels $(\mathrm{p}<0.001)$ than the controls. The prevalence of $H$. pylori infection was higher among the cases $(84.5 \%)$ than the controls (40.4\%). These variables might be associated with the GC risk and, therefore, were included in the subsequent statistical analyses that considered potential confounders. The total energy intake and DII score of the cases were significantly higher than those of the controls $(\mathrm{p}<0.001)$. However, no differences were found in the distribution of a family history of GC or alcohol consumption between the cases and controls. Additionally, regarding age and sex, there was no difference because the participants were matched beforehand.

Association between the DII score and risk of GC. Table 2 presents the associations between the tertile ranges of the DII score and GC risk. To confirm the association between the DII score and GC, Model 1 was adjusted for potential confounding factors, such as regular exercise, education and smoking status, while Model 2 included the $H$. pylori infection status along with the variables included in Model 1 . In the crude model, the participants in the highest DII group had a 1.70-fold higher GC risk than those in the lowest DII group (odds ratios (OR), 1.70; 95\% confidence intervals (CI) 1.24-2.33). This association was also significant after adjusting 


\begin{tabular}{|c|c|c|c|c|c|c|}
\hline \multirow[b]{2}{*}{ DII } & \multicolumn{2}{|l|}{$\mathbf{N}(\%)$} & \multicolumn{3}{|l|}{ OR $(95 \% \mathrm{CI})$} & \multirow[b]{2}{*}{$P$ interaction } \\
\hline & \begin{tabular}{|l|} 
Control \\
\end{tabular} & Case & \begin{tabular}{|l|} 
Crude \\
\end{tabular} & Model 1 & Model 2 & \\
\hline \multicolumn{7}{|l|}{ Total } \\
\hline $\mathrm{T} 1$ & $251(33.38)$ & $91(24.40)$ & 1 & 1 & 1 & \\
\hline $\mathrm{T} 2$ & $251(33.38)$ & $128(34.32)$ & $1.41(1.02-1.94)$ & $1.36(0.97-1.90)$ & $1.39(0.96-2.02)$ & \\
\hline $\mathrm{T} 3$ & $250(33.24)$ & 154 (41.28) & $1.70(1.24-2.33)$ & $1.38(0.99-1.93)$ & $1.41(1.00-2.06)$ & \\
\hline $\mathrm{P}$ trend & & & & 0.06 & 0.07 & \\
\hline Men & & & & & & 0.014 \\
\hline $\mathrm{T} 1$ & $163(33.48)$ & $68(28.1)$ & 1 & 1 & 1 & \\
\hline $\mathrm{T} 2$ & $162(33.26)$ & $88(36.36)$ & $1.19(0.80-1.79)$ & $1.34(0.89-2.03)$ & $1.25(0.79-1.96)$ & \\
\hline T3 & $162(33.26)$ & $86(35.54)$ & $1.29(0.87-1.93)$ & $1.04(0.69-1.57)$ & $0.99(0.63-1.58)$ & \\
\hline $\mathrm{P}$ trend & & & & 0.76 & 0.9 & \\
\hline \multicolumn{7}{|l|}{ Women } \\
\hline $\mathrm{T} 1$ & 89 (33.58) & $28(21.4)$ & 1 & 1 & 1 & \\
\hline $\mathrm{T} 2$ & $88(33.21)$ & $34(25.9)$ & $1.23(0.69-2.21)$ & $1.07(0.58-1.97)$ & $1.37(0.71-2.65)$ & \\
\hline T3 & $88(33.21)$ & $69(52.7)$ & $2.49(1.48-4.28)$ & $1.99(1.15-3.50)$ & $2.27(1.25-4.19)$ & \\
\hline$P$ trend & & & & 0.007 & 0.004 & \\
\hline
\end{tabular}

Table 2. Associations between the dietary inflammatory index (DII) score and gastric cancer risk. Model 1: adjusted by smoking status, education, and regular exercise for the total and men and adjusted by education and regular exercise for the women. Model 2: adjusted by smoking status, education, regular exercise, and Helicobacter pylori infection for the total and men and adjusted by education, regular exercise and Helicobacter pylori infection for the women. Criteria for DII: in total, T1 $<-0.77,-0.77<\mathrm{T} 2<2.01, \mathrm{~T} 3>2.01$; in men, $\mathrm{T} 1<-0.17,-0.17<\mathrm{T} 2<2.93, \mathrm{~T} 3>2.93$; in women, $\mathrm{T} 1<-1.59,-1.59<\mathrm{T} 2<1.41, \mathrm{~T} 3>1.41$. $\mathrm{P}$ interaction is the p-value of the interaction between sex and the DII. OR, odds ratio; $95 \%$ CI, 95\% confidence interval.

\begin{tabular}{|c|c|c|c|c|c|c|}
\hline \multirow[b]{2}{*}{ Gene (rs ID) } & \multirow[b]{2}{*}{ Allele } & \multicolumn{2}{|l|}{ N (\%) } & \multicolumn{3}{|l|}{ OR $(95 \% \mathrm{CI})$} \\
\hline & & Control & Case & Crude & Model 1 & Model 2 \\
\hline \multicolumn{7}{|l|}{ Total $(\mathrm{N}=1,125)$} \\
\hline \multirow{2}{*}{ TNF (rs1799964) } & TT & $475(63.2)$ & $230(61.7)$ & 1 & 1 & 1 \\
\hline & $\mathrm{C}+$ & $277(36.8)$ & $143(38.2)$ & $1.07(0.82-1.38)$ & $1.08(0.84-1.41)$ & $1.07(0.80-1.43)$ \\
\hline \multicolumn{7}{|l|}{$\operatorname{Men}(\mathrm{N}=729)$} \\
\hline \multirow{2}{*}{ TNF (rs1799964) } & TT & $301(61.8)$ & $154(63.6)$ & 1 & 1 & 1 \\
\hline & $\mathrm{C}+$ & $186(38.2)$ & $88(36.4)$ & $0.92(0.67-1.27)$ & $1.01(0.72-1.42)$ & $0.94(0.64-1.38)$ \\
\hline \multicolumn{7}{|l|}{ Women $(\mathrm{N}=396)$} \\
\hline \multirow{2}{*}{ TNF (rs1799964) } & TT & $174(65.7)$ & $76(58.0)$ & 1 & 1 & 1 \\
\hline & $\mathrm{C}+$ & $91(34.3)$ & $55(42.0)$ & $1.38(0.90-2.13)$ & $1.44(0.91-2.25)$ & $1.72(0.96-2.62)$ \\
\hline
\end{tabular}

Table 3. Associations between tumor necrosis factor (TNF) genetic polymorphisms and the gastric cancer risk in the dominant model. Model 1: adjusted by smoking status, education, and regular exercise for the total and men and adjusted by education and regular exercise for the women. Model 2: adjusted by smoking status, education, regular exercise, and Helicobacter pylori infection status for the total and men and adjusted by education, regular exercise and Helicobacter pylori infection status for the women. The values in the table indicate N (\%), OR (odds ratios) and 95\% CI (95\% Confidence Intervals).

for all confounding factors (Model 2: OR, 1.41; 95\% CI 1.00-2.06). When stratified by sex, compared to the risk associated with the lowest DII score group, the women with the highest DII score showed an association with an increased risk of GC, but there was no significant association among the men (Model 1: OR, 1.99; 95\% CI 1.15-3.50 for women, OR,1.04; 95\% CI 0.69-1.57 for men; Model 2: OR, 2.27; 95\% CI 1.25-4.19 for women, OR, 1.06; $95 \%$ CI $0.63-1.78$ for men). The women also showed a trend of significantly increased GC risk as the DII increased ( $\mathrm{p}$-value for trend=0.007, 0.004 in Model 1, Model 2, respectively). Additionally, sex showed a significant interaction with the DII in the context of the GC risk ( $\mathrm{p}$ for interaction $=0.014$ ). Stratified by the $H$. pylori infection status, the association between the DII and GC was observed only in the H.pylori-positive group (fully adjusted model: OR, 1.62; 95\% CI 1.04-2.45), but the interaction between the DII and infection status was not significant $(\mathrm{p}=0.36)$ (Supplementary Table S2).

Association between a TNF polymorphism (rs1799964) and the risk of GC. The results of the association between a genetic polymorphism of TNF (rs1799964) and the GC risk are shown in Table 3. 


\begin{tabular}{|c|c|c|c|c|c|c|c|c|c|c|}
\hline \multirow[b]{2}{*}{ Gene (rs ID) } & \multirow[b]{2}{*}{ Allele } & \multirow[b]{2}{*}{ DII } & \multicolumn{2}{|l|}{$\mathrm{N}(\%)$} & \multirow{2}{*}{\begin{tabular}{|l|} 
Crude \\
OR $(95 \% \mathrm{CI})$
\end{tabular}} & \multirow[b]{2}{*}{$P$ interaction } & \multirow{2}{*}{\begin{tabular}{|l} 
Model 1 \\
OR $(95 \% \mathrm{CI})$
\end{tabular}} & \multirow[b]{2}{*}{$P$ interaction } & \multirow{2}{*}{\begin{tabular}{|l|} 
Model 2 \\
OR $(95 \% \mathrm{CI})$ \\
\end{tabular}} & \multirow{2}{*}{$\begin{array}{l}\mathbf{P} \\
\text { interaction }\end{array}$} \\
\hline & & & Control & Case & & & & & & \\
\hline \multicolumn{11}{|l|}{ Total $(\mathrm{N}=1,125)$} \\
\hline \multirow{4}{*}{ TNF (rs1799964) } & \multirow{2}{*}{ TT } & Low & $244(51.4)$ & $85(37.0)$ & 1 & 0.14 & 1 & 0.055 & 1 & 0.12 \\
\hline & & High & $231(48.6)$ & $145(63.0)$ & $1.80(1.31-2.49)$ & & $1.62(1.16-2.28)$ & & $1.59(1.10-2.31)$ & \\
\hline & \multirow{2}{*}{$\mathrm{C}+$} & Low & $132(47.7)$ & $61(42.7)$ & 1 & & 1 & & 1 & \\
\hline & & \begin{tabular}{|l|} 
High \\
\end{tabular} & $145(52.3)$ & $82(57.3)$ & $1.22(0.82-1.84)$ & & $1.00(0.63-1.52)$ & & $1.06(0.66-1.75)$ & \\
\hline \multicolumn{11}{|l|}{ Men $(\mathrm{N}=729)$} \\
\hline \multirow{4}{*}{ TNF (rs1799964) } & \multirow{2}{*}{ TT } & Low & $147(48.8)$ & $70(45.5)$ & 1 & 0.83 & 1 & 0.98 & 1 & 0.89 \\
\hline & & High & $154(51.2)$ & $84(54.5)$ & $1.21(0.82-1.79)$ & & $1.08(0.71-1.64)$ & & $1.03(0.64-1.65)$ & \\
\hline & \multirow{2}{*}{$\mathrm{C}+$} & Low & $85(45.7)$ & $36(40.9)$ & 1 & & 1 & & 1 & \\
\hline & & High & $101(54.3)$ & $52(59.1)$ & $1.29(0.78-2.16)$ & & $1.09(0.63-1.90)$ & & $1.17(0.64-2.14)$ & \\
\hline \multicolumn{11}{|l|}{ Women $(\mathrm{N}=396)$} \\
\hline \multirow{4}{*}{ TNF (rs1799964) } & \multirow{2}{*}{ TT } & Low & $92(52.9)$ & $22(28.9)$ & 1 & 0.042 & 1 & 0.035 & 1 & 0.068 \\
\hline & & \begin{tabular}{|l|} 
High \\
\end{tabular} & $82(47.1)$ & $54(71.1)$ & $2.75(1.56-4.98)$ & & $2.30(1.27-4.24)$ & & $2.55(1.36-4.92)$ & \\
\hline & \multirow{2}{*}{$\mathrm{C}+$} & Low & $40(44)$ & $23(41.7)$ & 1 & & 1 & & 1 & \\
\hline & & \begin{tabular}{|l|} 
High \\
\end{tabular} & $51(56)$ & $32(58.2)$ & $1.09(0.56-2.16)$ & & $0.78(0.37-1.65)$ & & $0.96(0.40-2.26)$ & \\
\hline
\end{tabular}

Table 4. Interaction of the TNF genetic polymorphism (dominant model) and DII score with the gastric cancer risk. Model 1: adjusted by smoking status, education, and regular exercise for the total and men and adjusted by education and regular exercise for the women. Model 2: adjusted by smoking status, education, regular exercise, and Helicobacter pylori infection status for the total and men and adjusted by education, regular exercise and Helicobacter pylori infection status for the women. Criteria for high and low DII groups: low $<0.724$, high $>0.724$ for total; low $<1.12$, high $>1.12$ for men; low $<0.038$, high $>0.038$ for women. The values in the table indicate N (\%), OR (odds ratios) and 95\% CI (95\% Confidence Intervals). P interaction is the p-value of the interaction between the DII and TNF genotype. OR, odds ratio; 95\% CI, 95\% confidence interval; TNF, tumor necrosis factor; DII, dietary inflammatory index.

Rs1799964 was not associated with the risk of GC (Model 1: OR, 1.08; 95\% CI 0.84-1.41, Model 2: OR, 1.07; 95\% CI 0.80-1.43).

Modifying effects of the TNF gene on the associations between the DII and GC risk. To identify whether the TNF gene modifies the association between the DII and GC risk, we performed a stratified analysis by individual genotype (Table 4). Compared to the risk in the low DII group, the TNF rs1799964 TT homozygotes in the high DII group showed a 1.62-fold increase in the GC risk (Model 1: OR, 1.62; 95\% CI 1.16-2.28). However, with C, there was no significant association between the DII and GC risk, although the interaction effect was suggestive ( $p$ for interaction $=0.055$ ). A significant interaction was observed among the women. Among the women, the TT homozygotes of rs1799964 in the high DII group exhibited an increased GC risk by 2.30 times compared to the risk in the low DII group (Model 1: OR, 2.30; 95\% CI 1.27-4.24). However, among the $\mathrm{C}$ carriers, there was no statistical association between the DII and GC, although there was a decrease in the GC risk in the high DII groups (Model 1: OR, 0.78; 95\% CI 0.37-1.65, p for interaction $=0.035$ ). When we further adjusted for the $H$. pylori infection status in Model 2, a significant association between high DII scores and the GC risk was also observed only in the TT genotype carriers, although the statistical significance of the interaction disappeared ( $\mathrm{p}$ for interaction $=0.068$ ). In the case of TT genotype, an inflammatory diet increased the risk of GC by nearly more than 2 times compared with the risk of the C carrier group when comparing the high and low DII groups (Model 2: OR, 2.55; 95\% CI 1.36-4.92 for TT genotype, OR, 0.96; 95\% CI 0.40-2.26 for $\mathrm{C}$ carrier). Among the men, a significant interaction between the DII and TNF gene polymorphism could not be identified (Model 1: OR, 1.08; 95\% CI 0.71-1.64 for TT genotype; OR, 1.09; 95\% CI 0.63-1.90 for C carrier, Model 2: OR, 1.03; 95\% CI 0.64-1.65 for TT genotype; OR, 1.17; 95\% CI 0.64-2.14 for C carrier). Stratified by the $H$. pylori infection status, the same results were observed in the $H$. pylori-positive group. The TT homozygotes showed an increased risk of GC in the high DII group (fully adjusted model: OR, 1.76; 95\% CI 1.13-2.73). However, among the individuals with the $\mathrm{C}$ allele, the risk of GC in the high DII group was decreased, although the association with DII and GC was not significant (OR, 0.98; 95\% CI 0.54-1.77, p for interaction $=0.034)$. But, no association with DII and GC or an interaction effect was observed in the H. pylori-negative group (Table 5).

\section{Discussion}

In the present case-control study of 1,125 participants (373 cases and 752 controls), we observed a significant association between the DII and risk of GC in women but not men. We also identified significant modification effects on the association between the DII and risk of GC according to a TNF genetic polymorphism. Among the individuals with high DII scores, C alleles in rs1799964 showed a protective effect against eating habits associated with GC risks compared to the effects observed in individuals with different genotypes. 


\begin{tabular}{|c|c|c|c|c|c|c|c|c|}
\hline \multirow[b]{2}{*}{ Infection status } & \multirow[b]{2}{*}{ Gene (rsID) } & \multirow[b]{2}{*}{ Allele } & \multirow[b]{2}{*}{ DII } & \multicolumn{2}{|l|}{$\mathrm{N}(\%)$} & \multicolumn{2}{|c|}{ OR $(95 \% \mathrm{CI})$} & \multirow[b]{2}{*}{ P interaction } \\
\hline & & & & $\begin{array}{l}\begin{array}{l}\text { Control } \\
(N=304)\end{array} \\
\end{array}$ & Case $(\mathrm{N}=315)$ & Crude & Fully adjusted & \\
\hline \multirow{4}{*}{$\begin{array}{l}\text { H. pylori posi- } \\
\text { tive }\end{array}$} & \multirow{4}{*}{$\begin{array}{l}\text { TNF } \\
\text { (rs1799964) }\end{array}$} & \multirow[b]{2}{*}{ TT } & Low & $99(52.1)$ & $68(35.4)$ & 1 & 1 & 0.034 \\
\hline & & & High & $91(47.9)$ & $124(64.6)$ & $\begin{array}{l}1.98(1.32- \\
2.99)\end{array}$ & $\begin{array}{l}1.76(1.13- \\
2.73)\end{array}$ & \\
\hline & & \multirow[b]{2}{*}{$\mathrm{C}+$} & Low & $53(46.5)$ & $54(43.9)$ & 1 & 1 & \\
\hline & & & High & $61(53.5)$ & $69(56.1)$ & $\begin{array}{l}1.11(0.67- \\
1.85)\end{array}$ & $\begin{array}{l}1.01(0.54- \\
1.77) \\
\end{array}$ & \\
\hline \multirow[b]{2}{*}{ Infection status } & \multirow[b]{2}{*}{ Gene (rsID) } & \multirow[b]{2}{*}{ Allele } & \multirow[b]{2}{*}{ DII } & \multicolumn{2}{|l|}{$\mathbf{N}(\%)$} & \multicolumn{2}{|c|}{ OR $(95 \% \mathrm{CI})$} & \\
\hline & & & & $\begin{array}{l}\text { Control } \\
(\mathrm{N}=448)\end{array}$ & Case $(\mathrm{N}=58)$ & Crude & Fully adjusted & P interaction \\
\hline \multirow{4}{*}{$\begin{array}{l}\text { H. pylori nega- } \\
\text { tive }\end{array}$} & \multirow{4}{*}{$\begin{array}{l}\text { TNF } \\
(r s 1799964)\end{array}$} & \multirow[b]{2}{*}{ TT } & Low & $145(50.9)$ & $16(42.1)$ & 1 & 1 & 0.83 \\
\hline & & & High & $140(49.1)$ & $22(57.9)$ & $\begin{array}{l}1.36(0.68- \\
2.75)\end{array}$ & $\begin{array}{l}1.38(0.68- \\
2.87)\end{array}$ & \\
\hline & & \multirow[b]{2}{*}{$\mathrm{C}+$} & Low & $79(48.5)$ & $7(35.0)$ & 1 & 1 & \\
\hline & & & High & $84(51.5)$ & $13(65.0)$ & $\begin{array}{l}1.75(0.68- \\
4.86)\end{array}$ & $\begin{array}{l}1.25(0.44- \\
3.74)\end{array}$ & \\
\hline
\end{tabular}

Table 5. Interaction of the TNF genetic polymorphism (dominant model) and DII score with the gastric cancer risk stratified by $H$. pylori infection. Fully adjusted model was adjusted by age, smoking status, education, and regular exercise. The values in the table indicate N (\%), OR (odds ratios) and 95\% CI (95\% Confidence Intervals). Criteria for high and low DII groups: in $H$. pylori positive: low $<0.707$, high $>0.707$; in $H$. pylori negative: low $<0.742$, high $>0.742$. P interaction is the p-value of the interaction between the DII and TNF genotype. OR, odds ratio; $95 \%$ CI, 95\% confidence interval; TNF, tumor necrosis factor; DII, dietary inflammatory index.

Chronic inflammation can contribute to the development of cancer through an inflammatory mediator, such as cytokines (e.g., TNF- $\alpha$ and IL) secreted by immune cells, leading to changes in the epigenome ${ }^{20}$. Although many GC studies focus on $H$. pylori infection, environment-induced inflammatory reactions or genetic differences can also increase the risk of GC. Among such environmental factors, we focused on diet factors considered to induce inflammation through oxidative stress reactions, and we could confirm that an inflammatory-inducing eating habit is more dangerous in women, which is consistent with previous research results ${ }^{21,22}$. These results may be attributed to differences in eating habits between men and women and the effects of sex hormones. According to previous studies investigating sex differences in the immune response, inflammation-related genes can be overexpressed in women due to differences in hormone conditions and rare genes on $\mathrm{X}$ chromosomes, and this overexpression results in poor prognoses among women suffering from chronic inflammatory diseases ${ }^{23,24}$. Additionally, in the present study, the men and women had different drinking habits. In the case of the women, $43 \%$ were current alcohol consumers, whereas $73 \%$ of the men were current alcohol consumers (Supplementary Table S1). Therefore, the results of the association may have differed according to sex.

Another factor related to the inflammatory response is the genetic predisposition of the host. In particular, single nucleotide polymorphisms (SNPs) present in the promoter of TNF have been shown to contribute to differences in individual inflammatory reactions $s^{3,5,25}$. Sugimoto et al. ${ }^{19}$ reported that $\mathrm{rs} 1799964 \mathrm{C}$ alleles were involved in the susceptibility to GC and can induce higher TNF production, especially in East Asian individuals. Additionally, rs1799964 T>C polymorphisms might be associated with a reduced risk of $H$. pylori infection ${ }^{18}$. Therefore, the association with GC risk in that region was expected, and a previous meta-analysis suggested the need for further studies to provide evidence supporting the association between TNF-1031 (rs1799964) and $\mathrm{GC}^{8,9}$, but such an association was not confirmed in our study. However, interestingly, according to our results, the effects of an inflammatory diet on the GC risk differ depending on the TNF rs1799964 genotype. The exact mechanism of this phenomenon has not been explained, but it is possible that the variation in the promoter region is related to gene expression ${ }^{6}$.

$T N F-\alpha$ is a multifunctional cytokine produced by monocytes and macrophages that plays an important role in promoting the inflammatory response and cell proliferation and inducing apoptosis ${ }^{6}$. Polymorphisms located in the promoter region of the TNF gene affect the transcription of theses genes ${ }^{6}$. Some studies have reported a correlation between polymorphism rs1799964 and the TNF mRNA expression level ${ }^{26,27}$. Nourian et al. ${ }^{28} \mathrm{dem}-$ onstrated that the level of TNF mRNA expression was reduced in individuals with the genotype TT compared with that in individuals with other genotypes. Considering the mechanism by which the substances contained in the diet induce the secretion of cytokines and cause the inflammatory cell response ${ }^{29}$, we assume that if cytokine secretion is genetically altered, it can be difficult to identify the same influence across different genetic types.

Our results suggest that inflammation-inducing eating habits can result in different outcomes depending on the individual's genetic background, and it is believed that dietary interventions considering individual genotypes could help prevent GC early on. In addition, when we conducted further stratification analysis by the $H$. pylori infection status, the results suggested that these risky diet patterns can cause different cancer development depending on the individual's genetic background. However, the interpretation requires caution, and studies involving larger samples are warranted because the number of cases in the H. pylori-negative group was very small. Additionally, other types of cytokines, such as the interleukin (IL) family (e.g., IL-17 and IL-6), contribute 
to the inflammatory response ${ }^{30,31}$. Indeed, many studies have reported abnormal IL concentrations in GC patients and suggested promising indicators of GC development ${ }^{32,33}$. Therefore, further studies are needed to identify whether genetic polymorphisms associated with other cytokines can modify the diet effect that increases the risk of cancer.

To the best of our knowledge, this study is the first to report a gene-diet interaction while particularly focusing on a gene functionally associated with secreted serum TNF. Another strength of this study is that we calculated an index score to reflect the inflammatory potential of a diet, assessed its association with the risk of GC and used it to examine interactions with genes, which can consider the overall intake conditions and an individual's genetic background rather than only one risk factor. However, our study has several limitations. First, because of the relatively small number of GC cases, we have insufficient statistical power. Second, although we had information regarding the cardiac or noncardiac cancer status of the GC cases, because the number of cases was small, we were unable to observe a difference in the GC risk according to cancer subtypes. Additionally, this study may have been affected by selection bias due to its hospital-based case-control study design.

In conclusion, our findings demonstrate that the inflammatory potential of diets is associated with an increase in the risk of GC, particularly among women. Although there was no evidence of an association between the TNF polymorphism and GC, rs1799964 may modulate the effect of diet on GC, and a pro-inflammatory diet had a greater effect in the general population who did not have a genetic variant. Therefore, these results may support dietary recommendations for GC prevention and therapy on the basis of gene-environment interactions. To prevent GC, it seems important to reduce the amount of food-induced inflammation and consume a diet reportedly associated with anti-inflammation, such as fruits and vegetables. Further evaluations of the associations of the dietary factors included in the DII calculation and studies of other cytokine genetic polymorphisms are necessary to better understand the heterogeneity in the etiology of GC.

\section{Methods}

Study population. The participants were recruited to participate in a GC research project by the National Cancer Center (NCC) in Korea between March 2011 and December 2014. The details of this study have been previously described ${ }^{34}$. In brief, cases who were diagnosed with GC 3 months before recruitment were defined as patients. Cases diagnosed with other cancers within 5 years, diabetes mellitus, or severe mental disease and pregnant women were excluded. The controls were selected among individuals who visited the Center for Cancer Prevention and Detection at the NCC, and subjects with a history of cancer, diabetes mellitus, gastric ulcers, and $H$. pylori treatment were excluded. The cases and controls were matched for sex and 5-year age distributions. In total, $373 \mathrm{GC}$ cases and 752 healthy controls were included in this study, and their genotype and dietary intake data were available (Fig. 1). All participants provided written informed consent, and the study protocol was approved by the Institutional Review Board of the NCC (IRB Number: NCCNCS-11-438). Additionally, all procedures used in this study were carried out in accordance with the guidelines of the Institutional Review Board of the NCC.

Genotype measurement. The genotyping and quality control process were presented in detail in a previous study ${ }^{35}$. In brief, genomic DNA was extracted from peripheral blood, and the Affymetrix Axiom Exom 319 Array (Affymetrix Inc., Santa Clara, CA) platform, including 318,983 variants, was used for genotyping. Genotype imputation was performed using the Asian population $(n=504)$ in 1,000 Genome haplotypes phase III integrated variant set release GRch37/hg19 (https://www.1000genomes.org/) as a reference panel. Genetic markers with a minor allele frequency $(\mathrm{MAF})<0.01$, call rate $<95 \%$, and deviation from the Hardy-Weinberg equilibrium $\left(P\right.$-value $\left.<1 \times 10^{-6}\right)$ were discarded. SHAPIT (v2.r837) and IMPUTE2 (2.3.2) were used to perform the phasing and SNP imputation, respectively. The quality control criteria were applied after filtering for an INFO score over 0.6. Finally, the genetic polymorphism (rs1799964) in the TNF promoter was selected.

Dietary assessment. Dietary assessment and calculation of the DII. The dietary intake of each participant was assessed using a 106-item semiquantitative food frequency questionnaire (SQFFQ). The validity and reproducibility of the SQFFQ have been previously reported ${ }^{36}$. The participants provided their individual average frequency of intake and portion sizes of specific foods in the year preceding the interview. These values were converted to obtain the daily nutrient intake using a scale with nine frequency categories (never or rarely, once a month, two or three times a month, once or twice a week, three or four times a week, five or six times a week, once a day, twice a day, and three times a day) and three portion size categories (small, medium, and large) included in the SQFFQ. The total energy and nutrient intake of each participant were analyzed by the Computer Aided Nutritional analysis program (CAN-PRO 4.0, Korean Nutrition Society, Seoul, Korea). The SQFFQ-derived data were used to calculate the DII scores of all participants. The details of the development ${ }^{37}$ and construct validation $^{38,39}$ of the DII have been previously described. The dietary data were used to calculate the $\mathrm{z}$-score of each food parameter for each individual. The global means and standard deviations of the food and nutrient intakes collected from 11 nations, including Korea, were used to calculate the $\mathrm{z}$-score. Then, the $\mathrm{z}$-score was converted to a percentile and centered by doubling the value and subtracting 1 . The centered percentile value was multiplied by the respective inflammatory effect score to obtain the food parameter-specific DII score ${ }^{37}$. The overall DII score was calculated as the sum of all available food parameter-specific DII scores. This study included the following 35 of the original 45 DII food parameters to generate the DII score: protein, fat, carbohydrate, fiber, monounsaturated fatty acid (MUFA), polyunsaturated fatty acid (PUFA), saturated fatty acid, n-3 fatty acids, n-6 fatty acids, cholesterol, thiamin, riboflavin, niacin, vitamin B6, vitamin B12, vitamin C, folic acid, vitamin $A$, vitamin $D$, vitamin $E$, $\beta$-carotene, iron, magnesium, selenium, zinc, garlic, ginger, onion, green tea flavan-3-ols, flavones, flavonols, flavanones, anthocyanidins, and isoflavones. Energy was not used to compute 


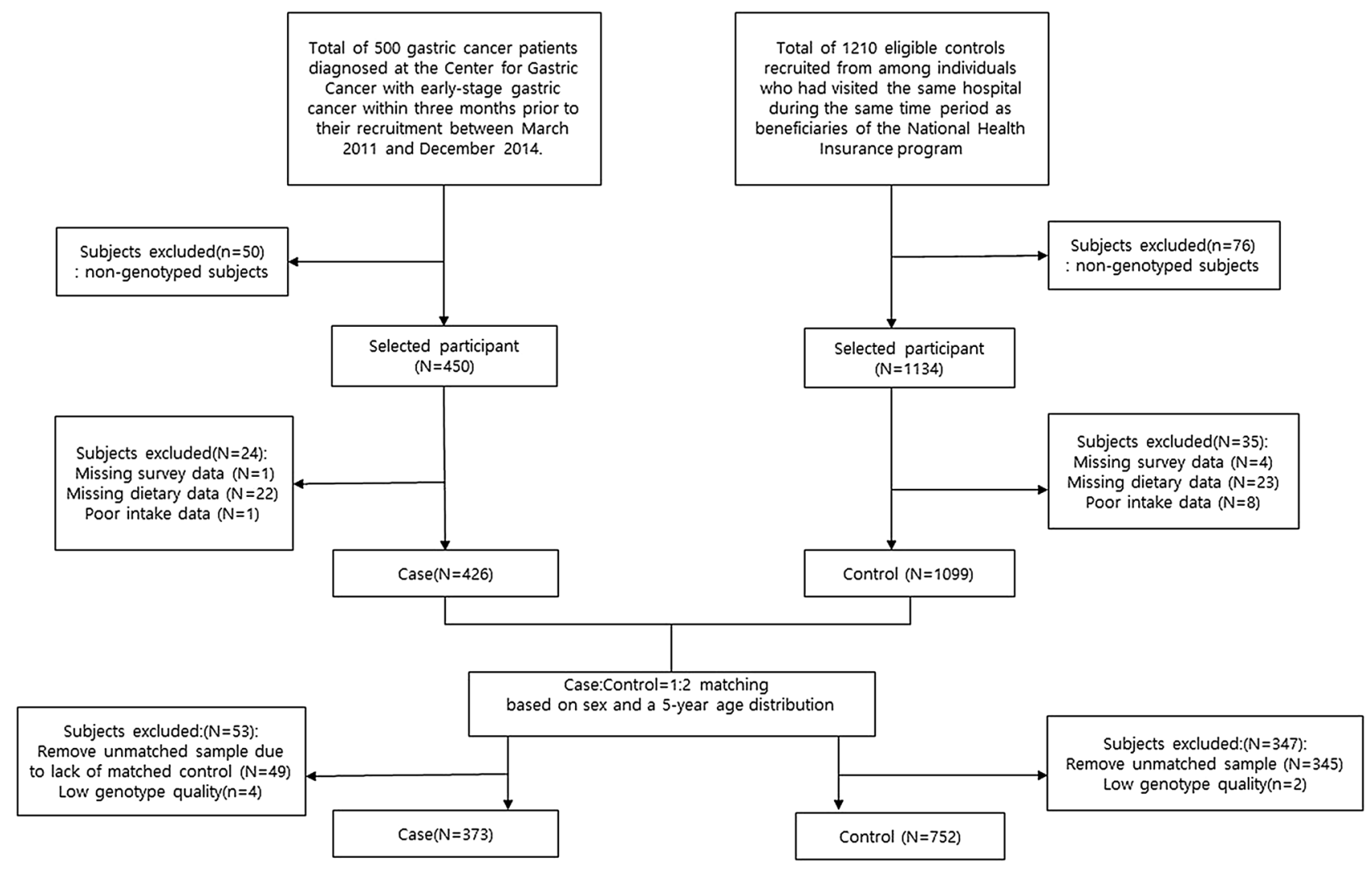

Figure 1. Flowchart of the selection of the study subjects in the study.

the DII because all components of the DII were adjusted for energy intake using the energy density approach, which was calculated per $1,000 \mathrm{kcal}$ of energy ${ }^{40}$. The world database was also standardized to $1,000 \mathrm{kcal} /$ day.

Statistical analyses. The difference in general characteristics between the cases and control subjects were analyzed by using the chi-square test (categorical variables) or t-test (continuous variables). The DII score was categorized into tertiles based on the control's score to investigate the association between inflammatory intake and the GC risk. The OR and 95\% CI of the GC risk were calculated for each group using a univariate logistic regression for the crude model and a multiple logistic regression with the lowest tertile as a reference group. The multivariable model (Model 1) was adjusted for age, sex, education level, smoking status, and physical activity. Model 2 additionally adjusted for the $H$. pylori infection status in Model 1 . A stratified analysis by sex and $H$. pylori infection status was performed, and the median value of each DII tertile was used as a continuous variable to test for trends. Genetic association analyses were performed in the dominant models. To analyze the interaction effects between the DII score and the genetic polymorphism, low- and high-score groups were categorized according to the median DII score of the control group. The interaction between the DII and SNPs was analyzed by using the likelihood ratio test between the models with and without the interaction term (DII*SNPs). All statistical analyses were performed using PLINK version $1.07^{41}$ and R software version 3.4.3.

Received: 10 February 2020; Accepted: 22 July 2020

Published online: 03 September 2020

\section{References}

1. Bray, F. et al. Global cancer statistics 2018: GLOBOCAN estimates of incidence and mortality worldwide for 36 cancers in 185 countries. CA Cancer J. Clin. 68, 394-424 (2018).

2. Jung, K.-W., Won, Y.-J., Kong, H.-J. \& Lee, E. S. Cancer statistics in Korea: Incidence, mortality, survival, and prevalence in 2016. Cancer Res. Treat. 51, 417 (2019).

3. Lippitz, B. E. Cytokine patterns in patients with cancer: A systematic review. Lancet Oncol. 14, e218-228. https://doi.org/10.1016/ S1470-2045(12)70582-X (2013).

4. Bockerstett, K. A. \& DiPaolo, R. J. Regulation of gastric carcinogenesis by inflammatory cytokines. Cell Mol. Gastroenterol. Hepatol. 4, 47-53. https://doi.org/10.1016/j.jcmgh.2017.03.005 (2017).

5. Persson, C., Canedo, P., Machado, J. C., El-Omar, E. M. \& Forman, D. Polymorphisms in inflammatory response genes and their association with gastric cancer: A HuGE systematic review and meta-analyses. Am. J. Epidemiol. 173, 259-270 (2010).

6. El-Tahan, R. R., Ghoneim, A. M. \& El-Mashad, N. TNF-alpha gene polymorphisms and expression. SpringerPlus 5, 1508. https:// doi.org/10.1186/s40064-016-3197-y (2016). 
7. Lee, J. Y. et al. Association of polymorphism of IL-10 and TNF-A genes with gastric cancer in Korea. Cancer Lett. 225, 207-214. https://doi.org/10.1016/j.canlet.2004.11.028 (2005).

8. Guo, X.-F. et al. TNF- $\alpha-308$ polymorphism and risk of digestive system cancers: A meta-analysis. World J. Gastroenterol. 19, 9461 (2013).

9. Zheng, W. et al. The relationship between tumor necrosis factor- $\alpha$ polymorphisms and gastric cancer risk: An updated metaanalysis. Biomed. Rep. 7, 133-142. https://doi.org/10.3892/br.2017.934 (2017).

10. Hardman, W. E. Diet components can suppress inflammation and reduce cancer risk. Nutr. Res. Pract. 8, 233-240 (2014).

11. Samraj, A. N. et al. A red meat-derived glycan promotes inflammation and cancer progression. Proc. Natl. Acad. Sci. 112, 542-547 (2015).

12. Dumas, J. A. et al. Dietary saturated fat and monounsaturated fat have reversible effects on brain function and the secretion of pro-inflammatory cytokines in young women. Metabolism 65, 1582-1588 (2016).

13. Hu, F. B. Dietary pattern analysis: A new direction in nutritional epidemiology. Curr. Opin. Lipidol. 13, 3-9 (2002).

14. Yang, X. X. et al. Association of TGF-beta1, IL-4 and IL-13 gene polymerphisms with asthma in a Chinese population. Asian Pac. J. Allergy Immunol. 29, 273-277 (2011).

15. Hoang, B. V. et al. Effect of dietary vitamin C on gastric cancer risk in the Korean population. World J. Gastroenterol. 22, 6257-6267. https://doi.org/10.3748/wjg.v22.i27.6257 (2016).

16. Key, T. J. et al. Diet, nutrition and the prevention of cancer. Public Health Nutr. 7, 187-200 (2004).

17. Elsamanoudy, A. Z., Mohamed Neamat-Allah, M. A., Hisham Mohammad, F. A., Hassanien, M. \& Nada, H. A. The role of nutrition related genes and nutrigenetics in understanding the pathogenesis of cancer. J. Microsc. Ultrastruct. 4, 115-122. https://doi. org/10.1016/j.jmau.2016.02.002 (2016).

18. Sun, X. et al. Association between TNFA gene polymorphisms and Helicobacter pylori infection: A meta-analysis. PLoS ONE 11, $\mathrm{e} 0147410$ (2016).

19. Sugimoto, M. et al. Different effects of polymorphisms of tumor necrosis factor-alpha and interleukin-1 beta on development of peptic ulcer and gastric cancer. J. Gastroenterol. Hepatol. 22, 51-59 (2007).

20. Grivennikov, S. I. \& Karin, M. Inflammation and oncogenesis: A vicious connection. Curr. Opin. Genet. Dev. 20, 65-71 (2010).

21. Ryu, I. et al. The association between dietary inflammatory index (DII) and cancer risk in Korea: A prospective cohort study within the KoGES-HEXA study. Nutrients 11, 2560 (2019).

22. Lee, S. et al. Dietary inflammatory index and the risk of gastric cancer in a Korean population. Oncotarget 8, 85452 (2017).

23. Chamekh, M. \& Casimir, G. Editorial: Sexual dimorphism of the immune inflammatory response in infectious and non-infectious diseases. Front. Immunol. 10, 107-107. https://doi.org/10.3389/fimmu.2019.00107 (2019).

24. Lotter, H. \& Altfeld, M. Sex differences in immunity. Semin. Immunopathol. 41, 133-135. https://doi.org/10.1007/s00281-018-00728 $-x(2019)$.

25. Gorouhi, F., Islami, F., Bahrami, H. \& Kamangar, F. Tumour-necrosis factor-A polymorphisms and gastric cancer risk: A metaanalysis. Br. J. Cancer 98, 1443 (2008).

26. Chen, G. et al. Tumour necrosis factor-alpha (TNF- $\alpha$ ) gene polymorphism and expression in pre-eclampsia. Clin. Exp. Immunol. 104, 154-159 (1996).

27. Rad, R. et al. Cytokine gene polymorphisms influence mucosal cytokine expression, gastric inflammation, and host specific colonisation during Helicobacter pylori infection. Gut 53, 1082-1089 (2004).

28. Nourian, M. et al. Evaluation of tumor necrosis factor (TNF)- $a$ mRNA expression level and the rs1799964 polymorphism of the TNF- $a$ gene in peripheral mononuclear cells of patients with inflammatory bowel diseases. Biomed. Rep. 6, 698-702 (2017).

29. Ernst, P. The role of inflammation in the pathogenesis of gastric cancer. Aliment. Pharmacol. Ther. 13, 13-18 (1999).

30. Liu, J. et al. Association of IL-17A and IL-17F polymorphisms with gastric cancer risk in Asians: A meta-analysis. Hum. Immunol. 76, 6-12. https://doi.org/10.1016/j.humimm.2014.12.011 (2015).

31. Yuzhalin, A. The role of interleukin DNA polymorphisms in gastric cancer. Hum. Immunol. 72, 1128-1136. https://doi. org/10.1016/j.humimm.2011.08.003 (2011).

32. Madej-Michniewicz, A. et al. Evaluation of selected interleukins in patients with different gastric neoplasms: A preliminary report. Sci. Rep. 5, 14382. https://doi.org/10.1038/srep14382 (2015).

33. Błogowski, W., Madej-Michniewicz, A., Marczuk, N., Dołęgowska, B. \& Starzyńska, T. Interleukins 17 and 23 in patients with gastric neoplasms. Sci. Rep. 6, 37451. https://doi.org/10.1038/srep37451 (2016).

34. Lee, S. et al. Dietary n-3 and n-6 polyunsaturated fatty acids, the FADS gene, and the risk of gastric cancer in a Korean population. Sci. Rep. 8, 3823. https://doi.org/10.1038/s41598-018-21960-3 (2018).

35. Park, B. et al. Genome-wide association of genetic variation in the PSCA gene with gastric cancer susceptibility in a Korean population. Cancer Res. Treat. 51, 748-757. https://doi.org/10.4143/crt.2018.162 (2019).

36. Ahn, Y. et al. Validation and reproducibility of food frequency questionnaire for Korean genome epidemiologic study. Eur. J. Clin. Nutr. 61, 1435 (2007).

37. Shivappa, N., Steck, S. E., Hurley, T. G., Hussey, J. R. \& Hébert, J. R. Designing and developing a literature-derived, populationbased dietary inflammatory index. Public Health Nutr. 17, 1689-1696 (2014).

38. Shivappa, N. et al. A population-based dietary inflammatory index predicts levels of C-reactive protein in the Seasonal Variation of Blood Cholesterol Study (SEASONS). Public Health Nutr. 17, 1825-1833 (2014).

39. Tabung, F. K. et al. Construct validation of the dietary inflammatory index among postmenopausal women. Ann. Epidemiol. 25, 398-405. https://doi.org/10.1016/j.annepidem.2015.03.009 (2015).

40. Willett, W. C., Howe, G. R. \& Kushi, L. H. Adjustment for total energy intake in epidemiologic studies. Am. J. Clin. Nutr. 65, 1220-1228. https://doi.org/10.1093/ajen/65.4.1220S (1997).

41. Purcell, S. et al. PLINK: A tool set for whole-genome association and population-based linkage analyses. Am. J. Hum. Genet. 81, 559-575. https://doi.org/10.1086/519795 (2007).

\section{Acknowledgements}

This research was supported by grants from the National Research Foundation of Korea (2018R1D1A1A09083876) and the National Cancer Center of Korea (1910330).

\section{Author contributions}

J.E.K. and J.K. conceived the research design; J.E.K. analyzed the data and wrote the manuscript of this paper; J.H.L. contributed to managing and standardizing the research data; I.J.C. and Y.I.K. contributed to collecting the data; J.H.S. conducted the research and provided a critical review; and J.K. had the primary responsibility for the final content. All authors read and approved the final manuscript.

\section{Competing interests}

The authors declare no competing interests. 


\section{Additional information}

Supplementary information is available for this paper at https://doi.org/10.1038/s41598-020-71433-9.

Correspondence and requests for materials should be addressed to J.K.

Reprints and permissions information is available at www.nature.com/reprints.

Publisher's note Springer Nature remains neutral with regard to jurisdictional claims in published maps and institutional affiliations.

Open Access This article is licensed under a Creative Commons Attribution 4.0 International License, which permits use, sharing, adaptation, distribution and reproduction in any medium or format, as long as you give appropriate credit to the original author(s) and the source, provide a link to the Creative Commons licence, and indicate if changes were made. The images or other third party material in this article are included in the article's Creative Commons licence, unless indicated otherwise in a credit line to the material. If material is not included in the article's Creative Commons licence and your intended use is not permitted by statutory regulation or exceeds the permitted use, you will need to obtain permission directly from the copyright holder. To view a copy of this licence, visit http://creativecommons.org/licenses/by/4.0/.

(c) The Author(s) 2020 